\title{
IS THE POSITION OF THE FEMUR-TIBIA JOINT UNDER FEEDBACK CONTROL IN THE WALKING STICK INSECT?
}

\section{FORCE MEASUREMENTS}

\author{
BY H. CRUSE \\ $F B$ Biologie der Universität Kaiserslautern, FRG
}

(Received 27 May I980)

\begin{abstract}
SUMMARY
It is known that a feedback system is involved in the position control of the femur-tibia joint of a fixed stick insect. Force measurements indicate that the control system also mediates negative feedback in the walking animal, the gain of the reflex loop and the half-time value of the reflex response being decreased. The biological significance of this effect is discussed. The results agree with similar experiments on man by other authors.
\end{abstract}

\section{INTRODUCTION}

In 1965 Bässler described a negative feedback mechanism which controls the position of the femur-tibia joint in the legs of the stick insect, Carausius morosus. In subsequent papers the properties of this system were investigated in detail (Bässler, I967, I972 $a, b$, 1973, 1974, г976; Godden, г974; Bässler, Cruse \& Pflüger, 1974; Bässler \& Storrer, r980; Storrer \& Cruse, 1977; Cruse \& Storrer, 1977). When the femur-tibia joint of the leg is flexed passively, the extensor muscle of this joint is excited to oppose this movement. A similar response occurs in the flexor muscle when the joint is extended. In most experiments the femoral chordotonal organ was stimulated directly (rather than by bending the femur-tibia joint) as this is the feedback transducer of the system.

In all of these previous experiments the animals were fixed and normally did not show any active movements, other than those elicited by stimulation of the chordotonal organ. When such animals attempted to perform active movements as a result of mechanical stimulation, for example by touching the abdomen, the system shows a different behaviour (Bässler, 1973, 1974, 1976). After such stimulation, relaxation of the chordotonal organ (corresponding to an extension of the femur-tibia joint) does not elicit a significant reaction of the flexor muscle. The negative feedback system seems therefore to be absent in this situation. In contrast, extension of the chordotonal organ (corresponding to a flexion of the femur-tibia joint) produces excitation of the flexor muscle. This could result from the system switching from negative to partial positive feedback, a mechanism which seems to depend upon the internal state of the -imal. How the system behaves during walking is unknown and is investigated in this paper. 


\section{METHODS}

It is not possible to stimulate the chordotonal organ, by moving the receptor apodeme with fine forceps, in a free-walking stick insect. An alternative method was therefore devised in which adult female stick insects (Carausius morosus) walked on a horizontal path of $30 \mathrm{~mm}$ in width. A small piece of the margin of the path (5 $\mathrm{mm}$ wide, $8 \mathrm{~mm}$ long) was cut away and then fixed to a forcemeter (Hellige UL 5०p) so as to form a small platform (Cruse, 1976). The animal was then allowed to walk over the path. When the animal then touched the platform, the force exerted during stance phase could be measured. In these experiments only the component of force parallel to the transverse axis of the body (lying in the horizontal plane and perpendicular to the long axis of the body) was measured. Such a force directed toward the body is positive (Cruse, I976). In addition, the forcemeter together with the platform could be moved by hand, perpendicular to the long axis of the insect's body. During the stance phase of the leg - an additional flexion (F) or extension (E) of the femur-tibia joint - could thus be superimposed on the walking movement of the leg (Fig. I). The duration of the platform movement ('stimulus ramp') was about $200 \mathrm{~ms}$.

Movement of the platform to or from the body changes the femur-tibia angle for, during stance phase, the middle leg is orientated more nearly perpendicular to the longitudinal axis of the body than the front or hind legs. With the latter the thoraciccoxal angle would be altered and, therefore, only the middle legs were investigated. The platform was moved inward or outward by $5 \mathrm{~mm}$. With the femur of the middle leg standing perpendicular to the long axis of the body this movement produced a change of $35^{\circ}$ in the femur-tibia joint, $10^{\circ}$ in the coxa-trochanterofemur joint and $0^{\circ}$ in the thoracic-coxal joint. The position of the platform was measured by an inductive position transducer (Hellige WL ${ }_{50}$ ) and recorded together with the force values on a 2-channel pen recorder (Hellige $\mathrm{He} \mathrm{i}$ 8). In control experiments the receptor apodeme of the femoral chordotonal organ was cut as described earlier (e.g. Bässler, 1965).

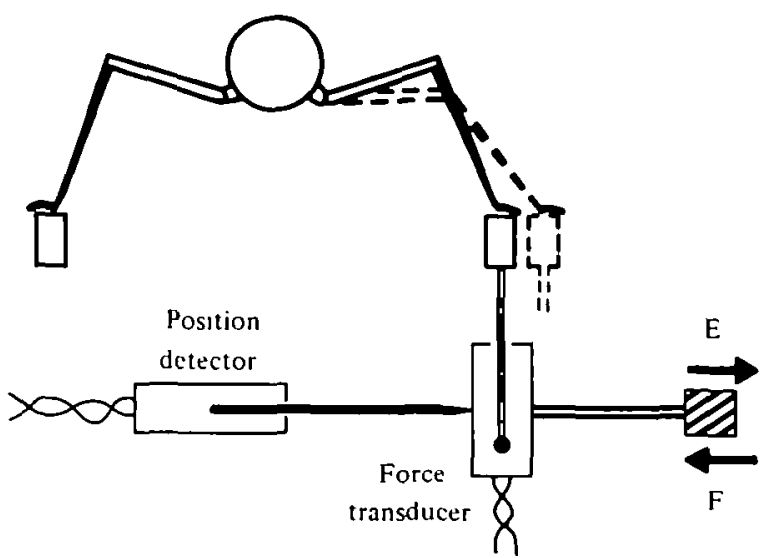

Fig. I. Schematic cross-section through an animal with a middle leg standing on the platform of the experimental device. 


\section{RESULTS}

\section{The standing animal}

As the experimental device differs from that used by previous authors, the experiments with standing animals had to be repeated. To do this, a free animal was placed on the walking path so that a middle leg stood on the platform. The platform was then moved stepwise outwards or inwards so as to extend or flex the femur-tibia joint. As expected from earlier observations, the response to extension of the femur-

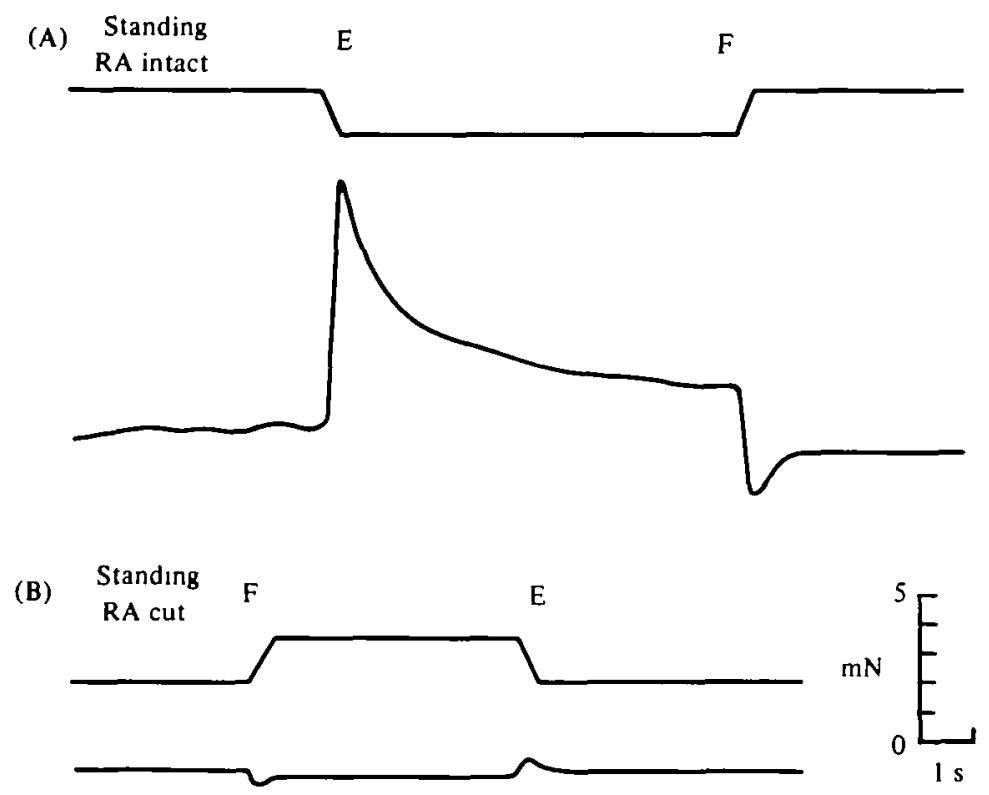

Fig. 2. Typical force response of a standing animal; (A) intact and (B) with the receptor apodeme cut. F, flexion; $E$, extension of the femur-tibia joint. Upper trace : position of the platform of the force transducer. Lower trace : forces. Positive forces are directed towards the body.

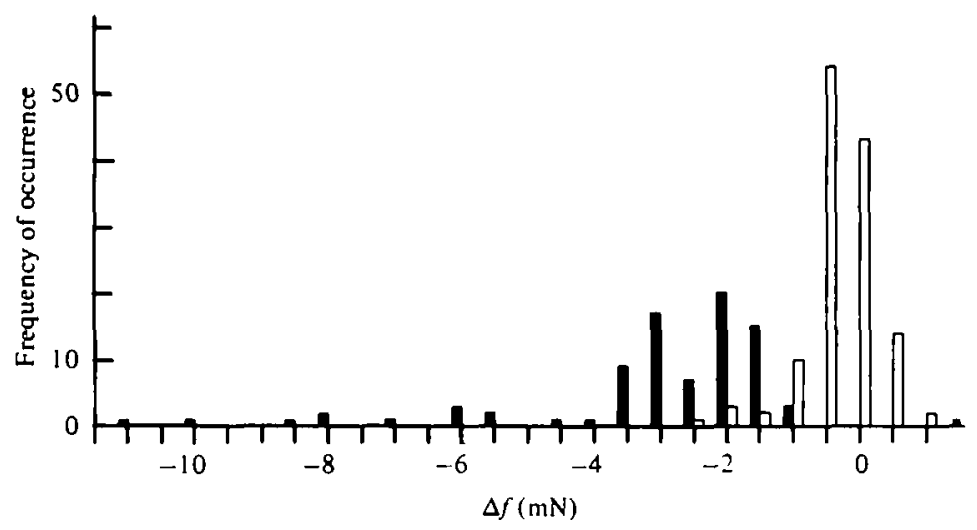

Fig. 3. The change of the force value $(\Delta f)$ during an imposed flexion. Intact animal: black columns ( $n=84,6$ animals). Animals with cut receptor apodeme: white columns ( $n=132$, 6 animals). 


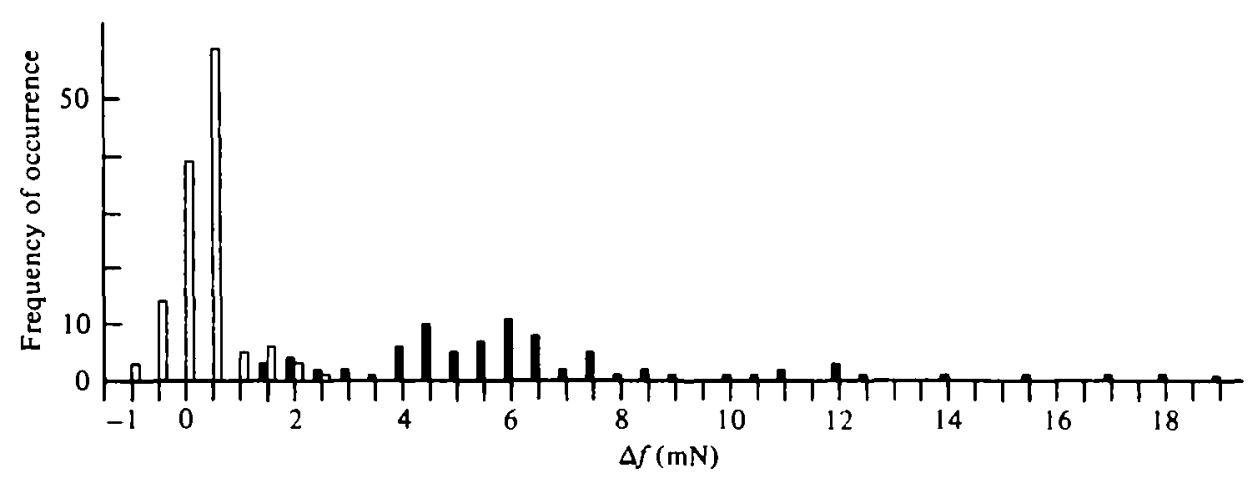

Fig. 4. The change of the force value during an imposed extension. Intact animals: black columns ( $n=83,6$ animals). Animals with cut receptor apodeme: white columns $(n=130$, 6 animals).

tibia joint has a higher amplitude than the response to flexion (Fig. 2 A). To obtain a quantitative estimate of the force reaction, the difference between the force value at the beginning and end of the stimulus ramp was measured. The distribution of these values is shown by the black columns in Fig. 3 (flexion) and Fig. 4 (extension). The arithmetic mean values are $-3.0 \mathrm{mN}$ (median $-2.5 \mathrm{mN}$ ) and $6.5 \mathrm{mN}$ (median $6.0 \mathrm{mN}$ ) respectively.

These results cannot be compared quantitatively with earlier ones obtained with fixed animals for two reasons. First, the position of the leg is more variable than in the experiments with fixed animals. Secondly, not only the torques developed by the muscles controlling the femur-tibia joint are measured but also those of the other joints (thoracic-coxal joint, coxa-trochanter joint). However, the contribution of the control mechanism of the femur-tibia joint can be estimated if the experiments are repeated with the receptor apodeme of the femoral chordotonal organ cut (Fig. 2B). The distribution of the values of these force changes is shown in Fig. 3 (flexion) and Fig. 4 (extension). The arithmetic mean values are $-0.3 \mathrm{mN}$ (median $0.5 \mathrm{mN}$ ) and $0.3 \mathrm{mN}$ (median $0.5 \mathrm{mN}$ ) respectively.

These results show that in the free-standing animal the main part of the response shown in Fig. $2 \mathrm{~A}$ results from stimulation of the femoral chordotonal organ. The second part of the response might be due to stimulation of other reflex loops in the femur-tibia joint, as well as in other joints of the leg, or to passive properties of the muscles.

Considering the decay of the force after the ramp a semi-logarithmic plot shows that the time course closely approximates to two additive exponential functions with different maximum amplitudes and time constants (see Fig. 5). The mean half-time value of the initial fast decay is $0.6( \pm 0.24) \mathrm{s}(\overline{\mathrm{x}} \pm$ S.D., $n=66)$, after flexion and 0.6 $( \pm 0.22) \&(n=59)$, after extension. To obtain the half times of the slow decay a separate series of experiments was performed (with 30 min between two consecutive ramps). These values are $38( \pm 12) s(n=13)$, after flexion, and $34( \pm 14) s(n=19)$, after extension. The ratio between the maximum amplitudes of the fast- and slowfalling exponential functions was $I \cdot I( \pm 0.5)(n=14)$, for the response to flexion, and $2 \cdot 0( \pm 1 \cdot 0)(n=19)$, for extension. The half-time value of the whole function (not 


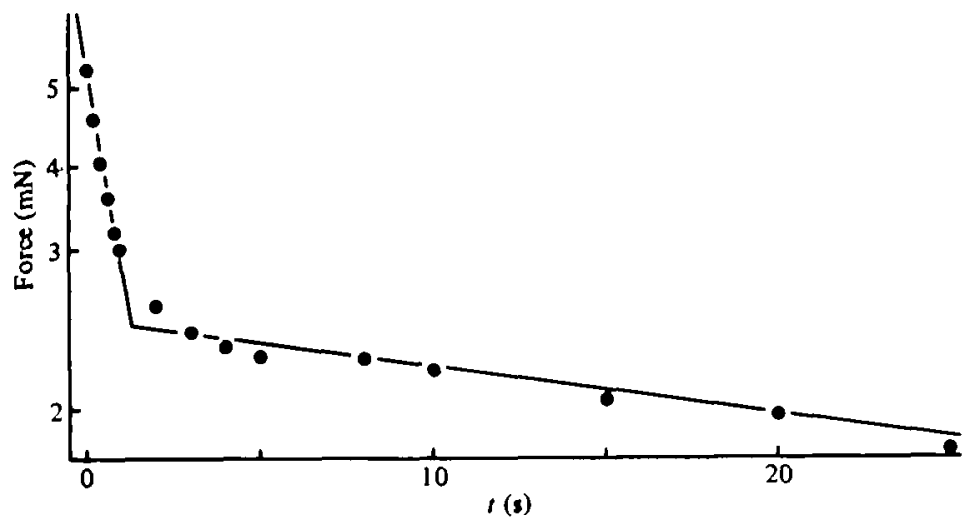

Fig. 5. The time course of an individual response to an imposed flexion. The two regression lines shown are calculated for the values between $O . I$ and $I 8$ and between 2 and 258 after the end of the ramp portion.

measured here) would thus be $\sim$ I s, after flexion, and somewhat shorter after extension. During the $30 \mathrm{~min}$ of the constant input value the force does not completely reach the final value. This difference amounts to $0.65( \pm 0.57) \mathrm{mN}(n=25)$.

\section{The walking animal}

For the middle leg of the intact walking animal the typical time course of the force component parallel to the transverse axis of the body shows a force at first directed towards the body ('positive force value') and then away from the body. However, the individual time course of the force varies considerably from step to step (Fig. 6).

Because of the changing force during the stance phase the responses cannot be seen as clearly as in the standing animal. Nevertheless the following results are obvious. When a flexion is superimposed on the movement of the femur-tibia joint, then during the ramp part of the stimulus the force value decreases (see Fig. $7 \mathrm{~A}, \mathrm{~B}$ ). When an extension movement is superimposed the force value is increased during the ramp part of the stimulus (Fig. $7 \mathrm{C}, \mathrm{D}$ ). This is not dependent on whether the force value before the stimulus is positive or negative (Fig. 7). To obtain quantitative results, the change of the force value during the ramp part of the stimulus was measured. The results for flexions of the femur-tibia joint are shown in Fig. 8. The

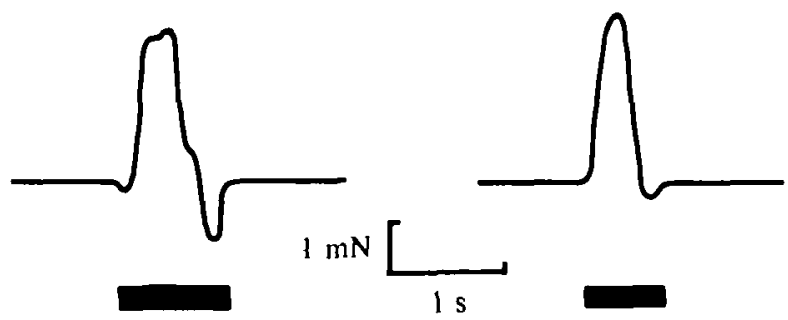

Fig. 6. Two examples showing the time course of the force of the middle leg of a walking animal during an undisturbed retraction (black bar). Positive forces (upward deflexion) are directed towards the body. 
A

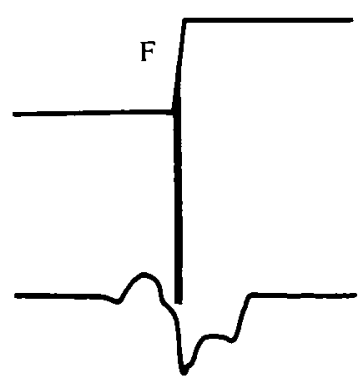

$1 \mathrm{mN}$

B

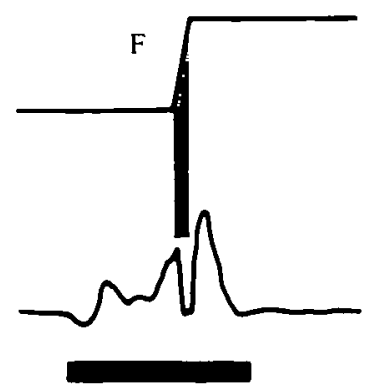

C

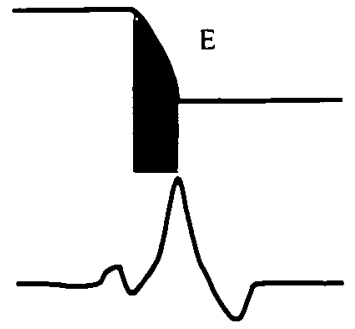

D

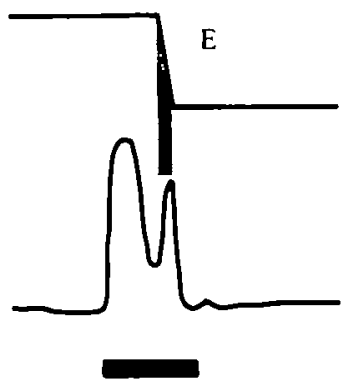

Fig. 7. Four examples showing the time course of the force for a walking animal, when a flexion (A, B) or an extension (C, D) is superimposed on the movement of the femur-tibia joint. The black bars show the duration of retraction.

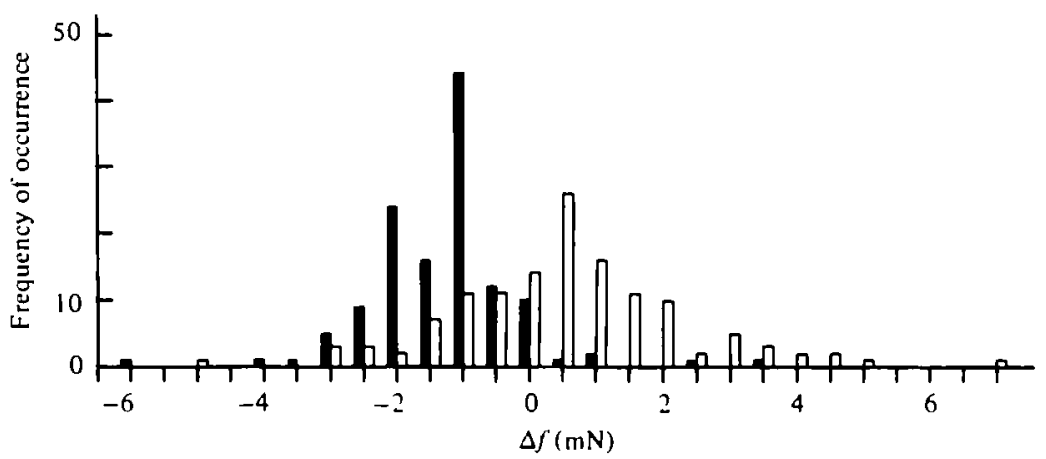

Fig. 8. The change of the force value during an imposed flexion in the walking animal. Intact animals: black columns ( $n=128$, I 3 animals). Animals with cut receptor apodeme: white columns ( $n=$ I3I, 4 animals). 


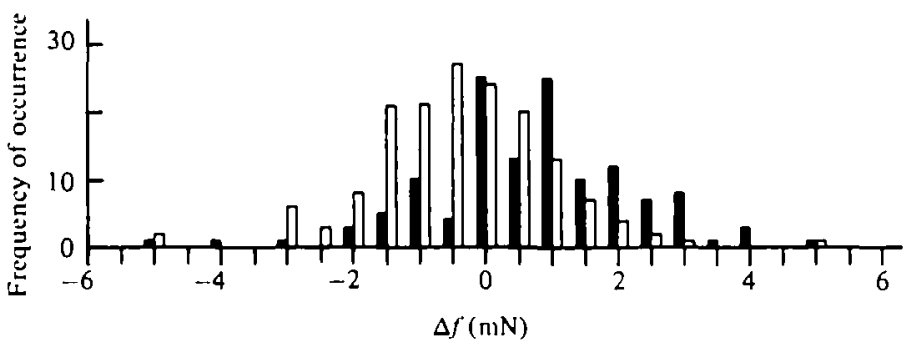

Fig. 9. The change of the force value during an imposed extension in the walking animal. Intact animals : black columns $(n=130,16$ animals). Animals with cut receptor apodeme: white columns ( $n=160,5$ animals).

arithmetic mean value is $-\mathrm{I} \cdot 24 \mathrm{mN}$ (median $-\mathrm{I} \mathrm{mN}$ ). The corresponding results obtained from animals with cut receptor apodeme are shown by white columns. The arithmetic mean value is $0.55 \mathrm{mN}$ (median $0.5 \mathrm{mN}$ ). The distributions are significantly different $\left(\chi^{2}\right.$-test, $\left.P \& 0.01 \%\right)$. Fig. 9 shows results obtained during an extension of the femur-tibia joint. The arithmetic mean value of intact animals (black columns) is $0.73 \mathrm{mN}$ (median I $\mathrm{mN}$ ). The mean value of animals with cut receptor apodeme (white columns) is $-0.39 \mathrm{mN}$ (median $-0.5 \mathrm{mN}$ ). Again the distributions are significantly different $\left(\chi^{2}\right.$-test, $\left.P \ll 0.01 \%\right)$. The distributions from the intact walking animal also differ significantly from those obtained from the standing animal with the receptor apodeme cut $\left(\chi^{2}\right.$-test, $\left.P \ll 0.01 \%\right)$. Comparison of Figs. 8 and 9 with Figs. 3 and 4 shows that in the walking animals there is much less scatter in the amplitude of the reflex response.

Because of the irregular time course of the forces, investigation of the response following the ramp is difficult. However, it appears that the reaction found in walking animals also differs in this respect from that of standing animals. After the ramp the force value returns to that before commencement of the stimulus. This time interval is much shorter in walking animals than in standing ones. The value of the half time can be roughly estimated as $100 \mathrm{~ms}$.

\section{DISCUSSION}

While both standing and walking there are obvious differences between the intact animals and thcse with the receptor apodeme cut. Thus during flexion of the femurtibia joint the mean values of the force changes are $-2.7 \mathrm{mN}$ in the standing and $-1.8 \mathrm{mN}$ in the walking animal. During an extension of the femur-tibia joint the differences are $6.2 \mathrm{mN}$ in the standing and $\mathrm{I} \cdot \mathrm{I} \mathrm{mN}$ in the walking animal. This shows that in addition to the change of the half times the gain of the reaction of the walking animal is reduced to about $65 \%$ during flexion and to about $20 \%$ during extension of that in the standing animal (using the force as an output value). This corresponds to results obtained by Wieneke \& Denier van der Gon (1974) in man, where the gain of the reflex loop of the wrist joint was diminished to $25-50 \%$ during active movements compared to the gain when the hand is held still (these authors used position not force as output value). The reaction in man is also asymmetric. The reflex gain is nigher when the disturbance input acts in the opposite direction to the intended 
movement and is smaller when it acts in the same direction. In stick insects the response to a flexion seems to be somewhat stronger than the response to an extension of the femur-tibia joint. Wieneke \& Denier van der Gon (1974) suggested that the reduced gain resulted from a decrease in the damping effect, caused by the feedback mechanism, increasing the speed of limb movements. This effect might be emphasized in the stick insect, for in addition to decrease in maximum amplitude (because of the smaller half time) the duration of the reflex response is also shortened.

The control experiments with the cut receptor apodeme indicate that the measured reaction did not result from inertia properties of the leg or the force transducer. However, the force measurements alone do not conclusively show that the measured reaction is a response of the femur-tibia control system. There are two other possibilities. If there are intra-leg reflexes between different joints, as found by Delcomyn (1971) in cockroaches, then stimulation of the femoral chordotonal organ, by bending the femur-tibia joint, would elicit a reaction in the coxa-trochanter joint. Secondly, cutting the receptor apodeme might decrease the tonus of the leg muscle. Therefore the possibility cannot be excluded that in both standing and walking animals only reactions of the elastic properties of the muscle systems are measured, and that these might be changed in the absence of excitation from the femoral chordotonal organ. However, electrophysiological recordings have shown that the femur-tibia control system is active in this experimental situation (Cruse \& Pflüger, $198 \mathrm{r}$ ). On the other hand, the electrophysiological experiments alone provide no quantitative measure of the gain or the half-time value of the whole system. Therefore, only with a combination of both methods is a sufficient description of the system possible.

In walking animals with severed receptor apodemes the reaction of the force differs slightly from zero and has a sign opposite to that of the reaction of the intact animal. This can, however, be explained by regarding the tibia as a passive strut. After extension the tibia is in an oblique position, pointing away from the body. Thus the force which the tibia exerts on the ground has a horizontal component with negative sign (pointing away from the body). After a flexion the tibia is in an oblique position, pointing towards the body. Correspondingly a horizontal component with positive sign will occur. The forces developed by the femur-tibia control system are added to these forces. These passive components are smaller in standing individuals. This is to be expected, for in an animal standing on six legs an individual one develops less force than in a walking insect, where less than six legs are in contact with the ground.

This research was supported by DFG ( $\left.\mathrm{Cr}_{58 / 2}\right)$.

\section{REFERENCES}

BXssler, U. (1965) Proprioreceptoren am Subcoxal- und Femur-Tibia-Gelenk der Stabheuschrecke Carausius morosus und ihre Rolle bei der Wahrnehmung der Schwerkraftrichtung. Kybernetik 2, I68-193.

BAssler, U. (1967). Zur Regelung der Stellung des Femur-Tibia-Gelenkes bei der Stabheuschrecke Carausius morosus in der Ruhe und im Lauf. Kybernetik 4, 18-26.

BXSSLER, U. (1972a). Der 'Kniesehnenreflex' bei Carausitus morosus: Ubergangsfunktion und Frequenzgang. Kybernetik 11, 32-50.

BAssler, U. (1972b). Der Regelkreis des Kniesehnenreflexes bei der Stabheuschrecke Carausius mororus: Reaktionen auf passive Bewegungen der Tibia. Kybernetik 12, 8-20. 
SLER, U. (1973). Zur Steuerung aktiver Bewegungen des Femur-Tibia-Gelenkes der Stabheuchrecke Carausius morosus. Kybernetik r3, 38-53.

BAssler, U. (1974). Vom femoralen Chordotonalorgan gesteuerte Reaktionen bei der Stabheuschrecke Carausius morosts: Messung der von der Tibia erzeugten Kraft im aktiven und inaktıven Tier. Kybernetik 16, 213-226.

BXssler, U. (1976). Reversal of a reflex to a single motoneuron in the stick insect Carousius morosus. Biol. Cybernetics 24, 47-49.

BAssler, U., Cruse, H. \& Pfloger, H.-J. ( 1974). Der Regelkreis des Kniesehnenteflexes bei der Stabheuschrecke Carausius morosus. Kybernetik 15, I I 7-I 25.

BXssler, U. \& Storrer, J. (1980). The neural basis of the femur-tibia control system in the stick insect Carausius morosis. I. Motoneurons of the extensor muscle. Binl. Cybernetics 38, 107-1 14.

Cruse, H. (1976). The function of the legs in the free walking stick insect, Carausius morosus. $\mathcal{Y}$. comp. Physiol. 112, 235-262.

Cruse, H. \& Pflüger, H.-J. (198I). Is the position of the femur-tibia joint under feedback control in the walking stick insect? II. Electrophysiological recordings. J. exp. Biol. 92, 97-107.

Cruge, H. \& Storrer, J. ( 1977 ). Open loop analysis of a feedback mechanism controlling the leg position in the stick insect Carausius morostus : comparison between experiment and simulation. Biol. Cybernetics 25, $143^{-1} 53$.

Delcomyn, F. (1971). Computer aided analysis of a locomotor leg reflex in the cockroach Periplaneta americana. Z. vergl. Physiol. 74, 427-445.

GoDdEN, D. H. (1 974). The physiological mechanism of catalepsy in the stick insect Carausius mororss (Br.). \%. comp. Physiol. 89, 25 I -274 .

Storrer, J. \& Cruse, H. (t977). Systemanalytische Untersuchung eines aufgeschnittenen Regelkreises, der die Beinstellung der Stabheuschrecke Carausius morosus kontrolliert: Kraftmessungen an den Antagonisten Flexor und Extensor tibiae. Biol. Cybernetics 25, 131-142.

Wieneke, G. H. \& Denier van Der GoN, J. J. (1974). Variations in the output impedance of the human motor system. Kybernetik $15,159-178$. 
